\title{
Analysis of the Features of a UPQC to Improve Power Quality in Smart Grids
}

\author{
J.G. Pinto, Carlos Couto, and João L. Afonso \\ Centro Algoritmi - University of Minho - Guimarães, Portugal \\ \{gabriel.pinto, joao.1.afonso\}@algoritmi.uminho.pt, \\ ccouto@dei.uminho.pt
}

\begin{abstract}
An UPQC (Unified Power Quality Conditioner) is an equipment composed by two active conditioners operating in a combined way. One of the active conditioners is connected in series with the electrical power system, allowing the compensation of problems in the system voltages. The other active conditioner is connected in parallel with the electrical system, and allows the compensation of current harmonics, current unbalances and power factor. In three-phase four-wire systems the parallel connected active conditioner also compensates the zero sequence current components, eliminating the neutral wire current. The UPQC operates in an automatic way, adjusting itself dynamically to the variations of the load and of the electrical system, keeping high levels of power quality in the voltages delivered to the load. At the same time, it only consumes from the electrical system the active power necessary to the load operation, in a balanced way through the three phases, and with sinusoidal currents. The compensation capabilities of the UPQC can be very useful to ensure high levels of power quality in the future Smart Grids, which are not characterized as a single technology or device, but rather as a vision of a distributed electrical system, supported by reference technologies, as Power Electronics Devices, Renewable Energy Resources, Energy Storage Systems (ESS), Advanced Metering Infrastructures (AMI), and Information and Communication Technologies (ICT).
\end{abstract}

Keywords:UPQC - Unified Power Quality Conditioner, Active Conditioners, Power Quality, Smart Grids, p-q Theory.

\section{Introduction}

The effective research in the area of semiconductor technologies in recent decades allowed the refinement and development of faster power semiconductors with lower operating losses [1-3]. The use of these electronic components enabled the optimization of production processes in terms of performance, controllability and cost, allowing the execution of tasks that were previously impossible. Due to the massive production, the price of power semiconductors decreased and the proliferation of these components has been so high that they are currently present in almost all electrical equipment. However, this technological evolution not only brought advantages. The equipment based on 
power semiconductors is responsible for causing many problems in the electrical power systems. The IEEE 1159 Standard classifies various electromagnetic phenomena in power systems that cause malfunction of equipment which is sensitive to disturbances in the power supply voltage, namely: oscillations, sags, swells, interruptions, undervoltages, overvoltages, harmonics, interharmonics, notches, noise, flicker, and frequency variation [4-8]. Some of these problems are caused by nonlinear loads and can be mitigated by specific equipment. Passive filters have been widely used as a solution to mitigate harmonic problems, but they present several limitations, namely: they only filter the frequencies for which they were previously tuned, and their operation cannot be limited to a certain load or installation. Furthermore, the interaction between passive filters and other loads may result in resonances with unpredictable results [9].In order to improve the mitigation achieved with passive filters and to minimize the impact of the power quality problems, in 1976 Gyugi and Strycula introduced the concepts of Active Filters [10]. Active filters, differently from passive filters, have the capability to dynamically adjust to the conditions of the electrical system, which consists in a great advantage. Starting from this new concept, in the last years various solutions based in power electronics to compensate power quality problems were investigated [11-18]. These types of equipment are usually designated in the literature as Active Conditioners. Some of these active conditioners are connected in parallel with the electrical grid and are designated as Shunt Active Conditioners. Other conditioners are connected in series with the electrical grid and are designated as Series Active Conditioners. The conjunct operation of shunt and series active conditioners originated a new concept of equipment called Unified Power Quality Conditioner (UPQC).

\section{Contribution to Internet of Things}

Studies conducted by several international organizations show that the economic losses caused by power quality problems are, nowadays, very high, and defends that little investment in equipment and procedures to increase power quality can result in an effective reduction in these losses [19]. According to EPRI (Electric Power Research Institute) problems related to power quality and supply interruptions cost to the U.S. economy more than 100 billion euros per year[20]. The European COPPER Institute - Leonardo Energy Initiative, estimates that the cost of electric quality problems in Europe is superior of 150 billion euros per year [21], [22]. Under this scenario, the development of equipment to improve power quality, such as the UPQC presented here, is a matter of utmost importance to ensure a favorable environment for the proper functioning of businesses, contributing to higher productivity and for the reduction of economic losses derived from power quality problems. In addition to the ability to mitigate power quality problems, the UPQC performs the measurement of several electrical signals that may be very useful for other devices connected to the Smart Grid. These measurements can be made available in an open way, through a bidirectional interface contributing to the Internet of Things. 


\section{UPQC Working Principle}

The UPQC is basically constituted by two conditioners that share the same DC Link. One is connected in series and the other is connected in parallel with the electrical system. The shunt (parallel connected)active conditioner works as a controlled current source and drains from the electrical system the undesired current components produced by the load. By the action of this active conditioner the phase currents upstream of the installation point (source currents) become sinusoidal, balanced, and in phase with the fundamental positive sequence component of the electrical system voltages. The series active conditioner works as a voltage source connected in series with the electrical system, allowing the compensating of voltage harmonics, sags, swells, and flicker (a cyclic variation of light intensity of lamps caused by fluctuation of the system voltage).The ability of the UPQC to transfer active power between the two active conditioners also allows the compensation of long term undervoltages and overvoltages, delivering to the load voltages with the desired amplitude, and with high levels of power quality. Fig. 1 shows a block diagram that explains in a simplified way the working principle of the UPQC. As it is represented in this figure, the voltage $\left(v_{F}\right)$ and the current $\left(i_{F}\right)$ produced by the UPQC make sinusoidal the current upstream and the voltage downstream of the connection point.

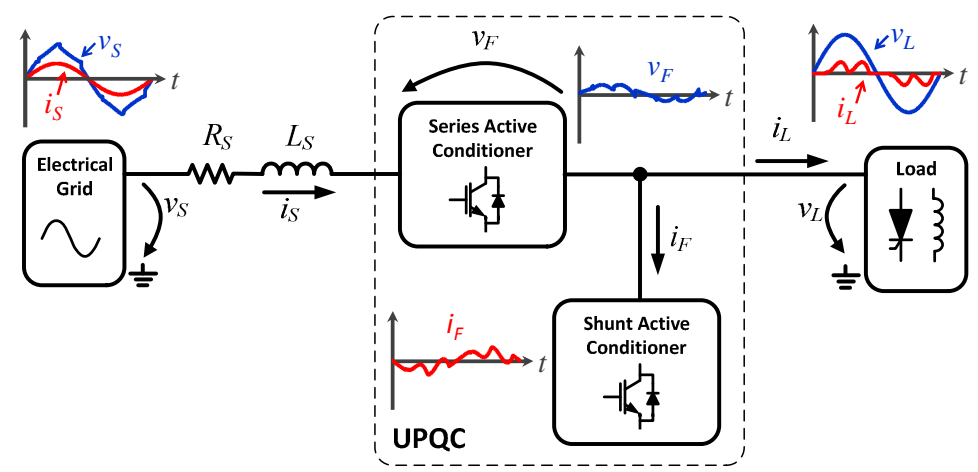

Fig. 1. UPQC (Unified Power Quality Conditioner) block diagram

\section{$4 \quad$ UPQC Simulation}

In order to validate the topology and the control algorithms it was developed a simulation model of the UPQC using the PSIM 9.0 software tool. Fig. 2 presents the schematic of the UPQC power circuit. In this figure it is possible two see the power inverters of the two active conditioners (sharing the same DC link capacitors $C_{l}$ and $C_{2}$ ) and the coupling inductors $\left(L_{1}\right.$ to $\left.L_{6}\right)$. For the proper operation of the UPQC, and to prevent short-circuits between the phases, it is necessary to galvanic isolate one of the active conditioners from the electrical system. In the presented UPQC topology the galvanic isolation is done by three isolating transformers used to connect the series active conditioner with the electrical system. 


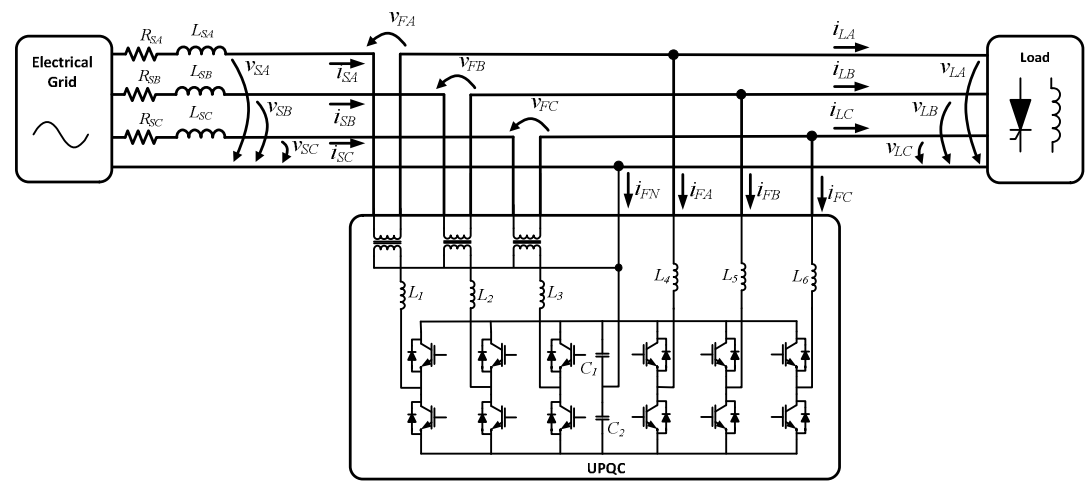

Fig. 2. Schematic of the UPQC power circuit

Several algorithms were developed to control the UPQC. The first algorithm consists in a digital Phase Locked Loop (PLL) and is responsible for the synchronization of the controller with the positive sequence of the fundamental component of the source voltages. The PLL receives the three source voltages and returns two sine waves with unitary amplitude that are used as synchronizing signals. These synchronizing signals are used to calculate the compensation currents by applying the concepts of the p-q theory, and also to generate the compensation voltages of the series active conditioner, by calculating the difference between the source voltages and the ideal desired load voltages.

Fig. 3 shows the voltage and current waveforms in the source, in the UPQC and in the load. Fig. 3 (a) shows the source voltages $\left(v_{S A}, v_{S B}, v_{S C}\right)$, which are distorted, unbalanced, and with low amplitude. Fig. 3 (b) shows the voltages produced by the series active conditioner $\left(v_{F A}, v_{F B}, v_{F C}\right)$ to compensate the source voltages. As it can be seen in the Fig. 3 (c), the load voltages $\left(v_{L A}, v_{L B}, v_{L C}\right)$ present sinusoidal waveforms with the same aptitude and with a constant phase shift of $120^{\circ}$. This means that, even with the voltages of the electrical system distorted and unbalanced, in a system with this UPQC in operation, the loads are always fed by a three phase balanced voltage system with constant and nominal amplitude. Fig. 3 (d) shows the waveforms of the phase currents consumed by the loads $\left(i_{L A}, i_{L B}, i_{L C}\right)$. It is possible to see that these currents present high distortions and that the current in the phase $B$ is significantly greater than the currents in the other two phases, which have similar amplitudes. With the currents produced by the shunt active conditioner $\left(i_{F A}, i_{F B}, i_{F C}\right)$, which are presented in Fig. $3(\mathrm{e})$, the source phase currents $\left(i_{S A}, i_{S B}, i_{S C}\right)$ become sinusoidal, balanced and in phase with the positive sequence of the fundamental component of the system voltages, as can be seen in the Fig. 3 (f). By the analysis of the Fig. 3 (f) it is possible to see that the shunt active conditioner produces a current $\left(i_{F N}\right)$, exactly equal to the current in the neutral wire of the load $\left(i_{L N}\right)$, which eliminates the current in the neutral wire upstream of the connection point $\left(i_{S N}\right)$. 
(a)

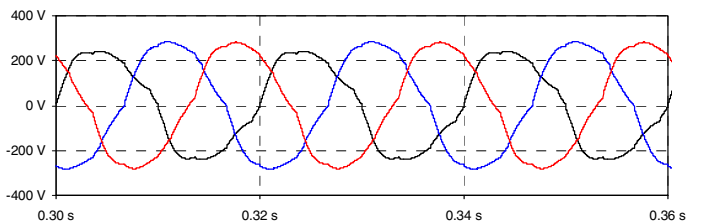

Source Voltages:

$-v_{S A}-v_{S B}-v_{S C}$

(b)

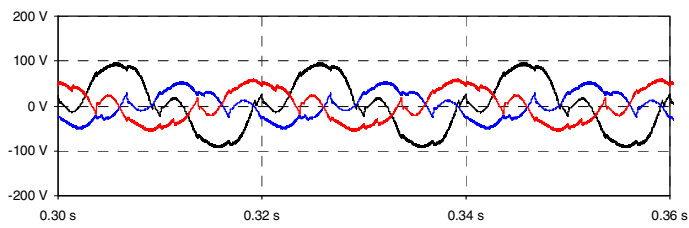

Series Active Conditioner Voltages:

(c)

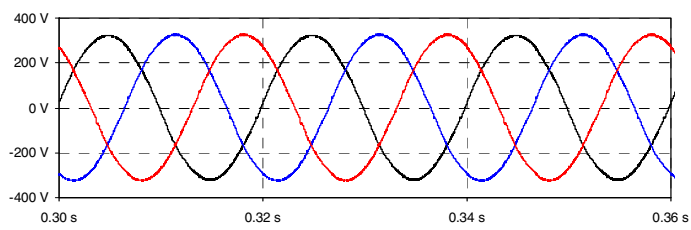

Load Voltages:

$-v_{L A}-v_{L B}-v_{L C}$

(d)

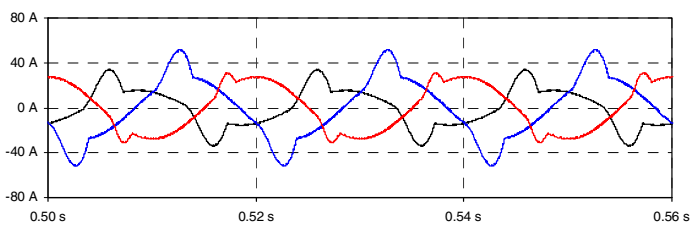

\section{Load Currents: \\ $-i_{L A}-i_{L B}-i_{L C}$}

(e)

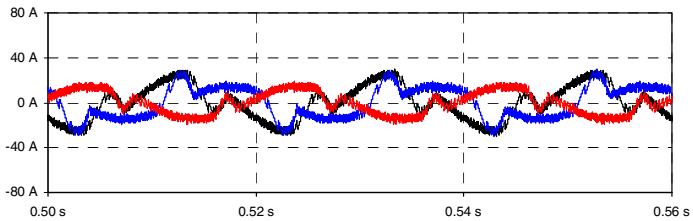

ShuntActive Conditioner Currents:

$-i_{F A}-i_{F B}-i_{F C}$

Source Currents:

$-i_{S A}-i_{S B}-i_{S C}$

(f)
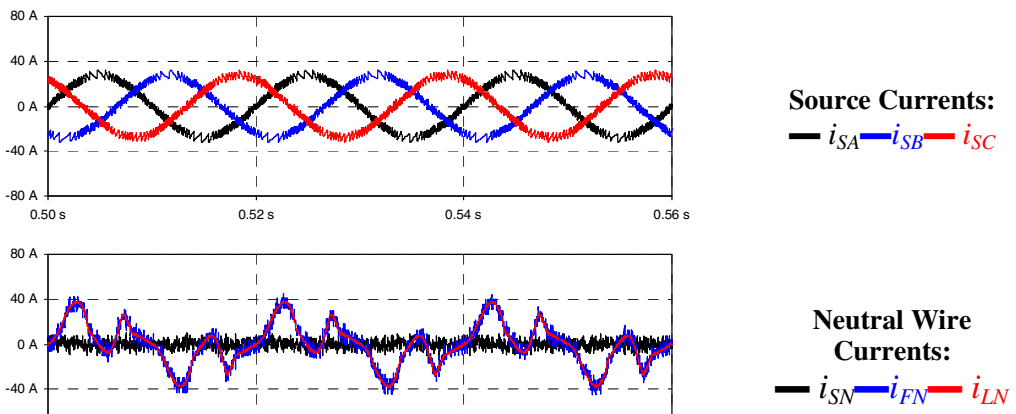

Fig. 3. Voltage and current waveforms in the source, in the UPQC and in the load: (a) Source voltages $\left(v_{S A}, v_{S B}, v_{S C}\right)$; (b) Series active conditioner voltages $\left(v_{F A}, v_{F B}, v_{F C}\right)$; (c) Load voltages $\left(v_{L A}, v_{L B}, v_{L C}\right)$;(d) Load currents $\left(i_{L A}, i_{L B}, i_{L C}\right)$; (e) Shunt active conditioner currents $\left(i_{F A}, i_{F B}, i_{F C}\right)$; (f) Source currents $\left(i_{S A}, i_{S B}, i_{S C}\right) ;(\mathrm{g})$ Neutral wire currents $\left(i_{S N}, i_{F N}, i_{L N}\right)$ 


\section{$5 \quad$ UPQC Experimental Results}

In order to obtain experimental results, it was developed a laboratory prototype of the UPQC with the topology presented in Fig. 2. Fig. 4 shows some experimental results obtained with the UPQC laboratory prototype. Fig. 4 (a) shows the waveforms of the source voltages $\left(v_{S A}, v_{S B}, v_{S C}\right)$ and load currents $\left(i_{L A}, i_{L B}, i_{L C}, i_{L N}\right)$. Fig. 4 (b) shows the waveforms of the compensated load voltages $\left(v_{L A}, v_{L B}, v_{L C}\right)$ and source currents $\left(i_{S A}\right.$, $\left.i_{S B}, i_{S C}, i_{S N}\right)$.The source voltages are slightly distorted and with amplitude lower than desired. The load currents are highly distorted and unbalanced. The neutral wire current is high, not only due to the load unbalancing, but also to the high zero sequence harmonic contents of the load currents.

(a)

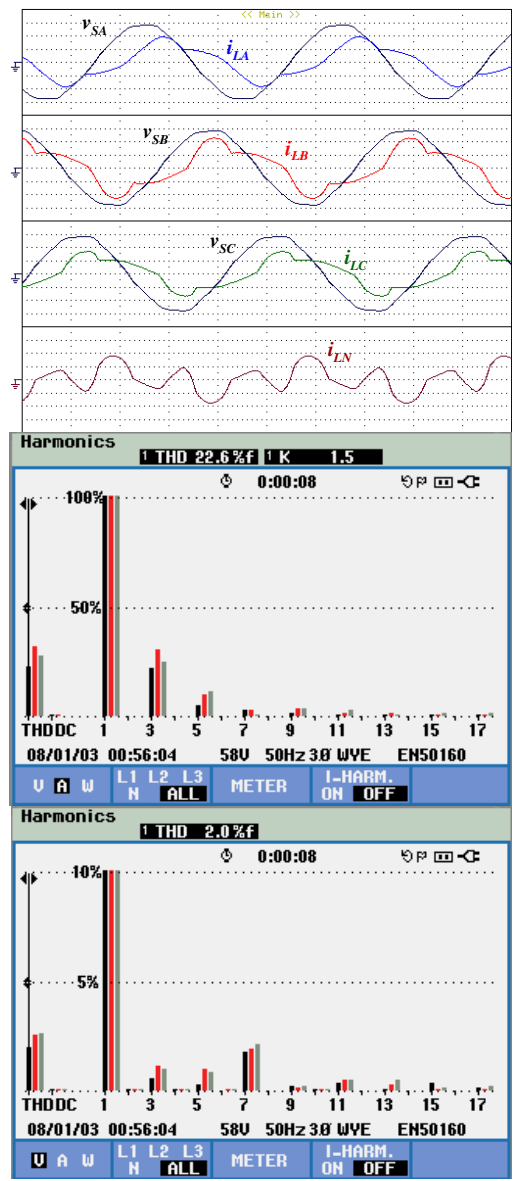

(b)

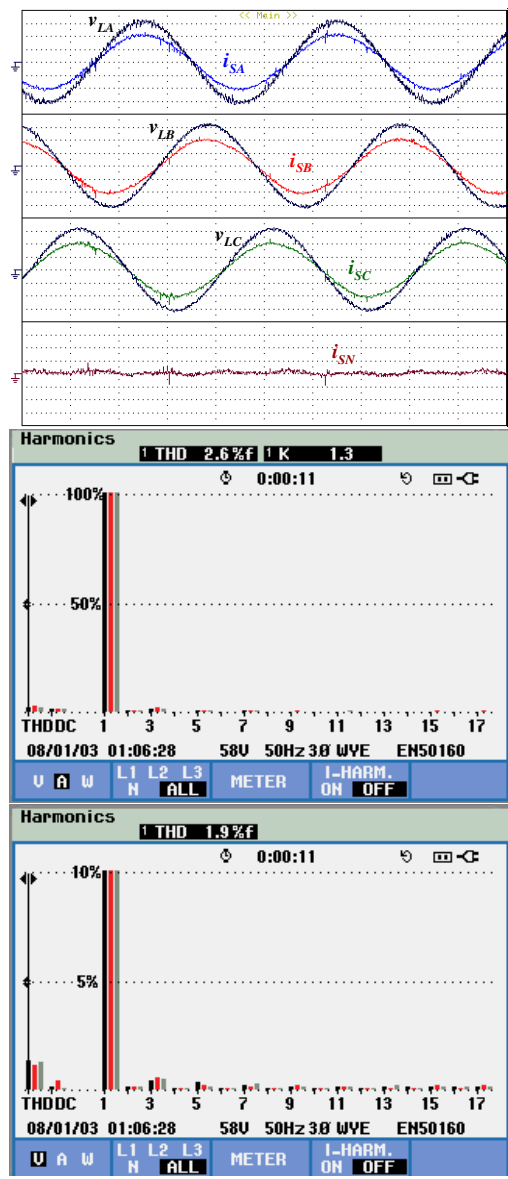

Fig. 4. Experimental results obtained with the UPQC laboratory prototype: (a)Load currents $\left(i_{L A}, i_{L B}, i_{L C}, i_{L N}-10 \mathrm{~A} / \mathrm{div}\right)$ and source voltages $\left(v_{S A}, v_{S B}, v_{S C}-25 \mathrm{~V} / \mathrm{div}\right)$; (b) Source currents $\left(i_{S A}\right.$, $\left.i_{S B}, i_{S C}, i_{S N}-10 \mathrm{~A} / \mathrm{div}\right)$ and load voltages $\left(v_{L A}, v_{L B}, v_{L C}-25 \mathrm{~V} / \mathrm{div}\right)$; (c) Spectral diagram of the load currents; (d) Spectral diagram of the source currents; (e) Spectral diagram of the source voltages;(f) Spectral diagram of the load voltages 
With the UPQC in operation the load voltages became sinusoidal and with the desired amplitude. The source currents became sinusoidal, balanced and in phase with the positive sequence of the fundamental component of the source voltages. The neutral wire current is practically eliminated. In terms of spectral analyses, as it can be seen in the Fig. 4 (c), the load currents present harmonics of various orders. In all the three phases the $3^{\text {rd }}$ order harmonic is the more relevant, however the $5^{\text {th }}$ is also present with a significant amplitude, especially in phase $C$. The shunt active conditioner of the UPQC compensates practically all the harmonic content, resulting in three source currents composed only by the fundamental, as it can be seen in Fig. 4 (d). As it can be seen in Fig. 4 (e), the source voltages present some harmonic contents, where the $7^{\text {th }}$ order harmonic is the most significant. The series active conditioner compensates almost all of the harmonics contents, as shown in Fig. 4 (f).

\section{Conclusions}

In this paper was presented an UPQC and it was demonstrated its capacity to compensate various problems related to the currents and voltages in the electrical power system. The topology and the control algorithms of the presented UPQC were validated trough computer simulations, and some simulation results are shown. The high-level validation of the introduced concepts and simulation model was guaranteed by experimental results, obtained with a prototype of the UPQC, which was developed in this PhD work. The unique features of the UPQC to compensate the load currents and the system voltages, and its capability to dynamically and instantaneously adapt to changes in the loads or in the power system, makes it a very interesting equipment to ensure high levels of power quality in future Smart Grids.

Acknowledgments. This work is financed by FEDER Funds, through the Operational Program for Competitiveness Factors - COMPETE, and by National Funds through the Foundation for Science and Technology of Portugal, under projects: PTDC/EEAEEL/104569/2008 and FCOMP-01-0124-FEDER-022674.

\section{References}

1. Adler, M.S., Owyang, K.W., Baliga, B.J., Kokosa, R.A.: The evolution of power device technology. IEEE Transactions on Electron Devices 31(11), 1570-1591 (1984)

2. Baliga, B.J.: Trends in power semiconductor devices. IEEE Transactions on Electron Devices 43(10), 1717-1731 (1996)

3. Hower, P.L.: Power semiconductor devices: an overview. Proceedings of the IEEE 76(4), 335-342 (1988)

4. Wagner, V.E., et al.: Effects of harmonics on equipment. IEEE Transactions on Power Delivery 8(2), 672-680 (1993)

5. Fuchs, E.F., Roesler, D.J., Kovacs, K.P.: Sensitivity of Electrical Appliances to Harmonics and Fractional Harmonics of the Power System's Voltage. Part II: Television Sets, Induction Watthour Meters and Universal Machines. IEEE Transactions on Power Delivery 2(2), 445-453 (1987) 
6. Fuchs, E.F., Roesler, D.J., Alashhab, F.S.: Sensitivity of Electrical Appliances to Harmonics and Fractional Harmonics of the Power SYSTEM's Voltage. Part I: Transformers and Induction Machines. IEEE Transactions on Power Delivery 2(2), 437444 (1987)

7. Bachry, A., Styczynski, Z.A.: An Analysis of Distribution System Power Quality Problems Resulting from Load Unbalance and Harmonics. In: IEEE PES, September 7-12, vol. 2 , pp. 763-766 (2003)

8. Fuchs, E., Masoum, M.: Power Quality in Power Systems and Electrical Machines. Elsevier (2008)

9. Afonso, J.L., Couto, C., Martins, J.: Active Filters with Control Based on the p-q Theory. IEEE Industrial Electronics Society Newsletter 47, 5-10 (2000)

10. Gyugyi, L., Strycula, E.C.: Active AC Power Filters. In: Proc. IEEE Ind. Appl. Ann. Meeting, vol. 19-C, pp. 529-535 (1976)

11. Akagi, H.: New trends in active filters for improving power quality. In: Proceedings of the 1996 International Conference on Power Electronics, Drives and Energy Systems for Industrial Growth, January 8-11, vol. 11, pp. 417-425 (1996)

12. Fujita, H., Akagi, H.: The unified power quality conditioner: The integration of series active filters and shunt active filters. In: 27th Annual IEEE Power Electronics Specialists Conference, June 23-27, vol. 1, pp. 494-501 (1996)

13. Pinto, J.G., Neves, P., Gonçalves, D., Afonso, J.L.: Field Results on Developed ThreePhase Four-Wire Shunt Active Power Filters. In: IECON 2009, Porto, Portugal, November 3-5 (2009)

14. Watanabe, E., Afonso, J., Pinto, J.G., Monteiro, L., Aredes, M., Akagi, H.: Instantaneous p-q Power Theory for Control of Compensators in Micro-Grids. In: IEEE ISNCC, Łagów, Poland, June 15-18 (2010)

15. Pinto, J.G., Exposto, B., Monteiro, V., Monteiro, L., Couto, C., Afonso, J.L.: Comparison of Current-Source and Voltage-Source Shunt Active Power Filters for Harmonic Compensation and Reactive Power Control. In: IECON 2012, Québec, Canada, October 25-28 (2012)

16. Pinto, J.G., Carneiro, H., Exposto, B., Couto, C., Afonso, J.L.: Transformerless Series Active Power Filter to Compensate Voltage Disturbances. In: Proceedings EPE 2011, Birmingham, United Kingdom, August 30-September 1, pp. 1-6 (2011)

17. Carneiro, H., Pinto, J.G., Afonso, J.L.: Single-Phase Series Active Conditioner for the Compensation of Voltage Harmonics, Sags, Swell and Flicker. In: ISIE 2011, Gdansk, Poland, June 27-30, pp. 384-389 (2011) ISBN: 978-1-4244-9310-4

18. Afonso, J.L., Pinto, J.G., Gonçalves, H.: Active Power Conditioners to Mitigate Power Quality Problems in Industrial Facilities. In: Zobaa, A. (ed.) Power Quality. InTech (2012) ISBN 980-953-307-532-2

19. Chapman, D.: The Cost of Poor Power Quality. Leonardo Power Quality Initiative European Copper Institute (2001)

20. Lineweber, D., McNulty, S.: The Cost of Power Disturbances to Industrial \& Digital Economy Companies. EPRI- Electric Power Research Institute (2001)

21. Poor Power Quality Costs European Business More than $€ 150$ Billion a Year. Leonardo Power Quality Initiative - European Copper Institute (2008)

22. Manson, J., Targosz, R.: European Power Quality Survey Report. Leonardo Power Quality Initiative - European Copper Institute (November 2008) 